\title{
The effect of anisotropy on amplitude versus offset (AVO) synthetic modelling in Derby field southeastern Niger delta
}

\author{
C. N. Ehirim ${ }^{1}$ N. O. Chikezie ${ }^{1}$
}

Received: 6 November 2016/Accepted: 11 February 2017/Published online: 27 February 2017

(C) The Author(s) 2017. This article is published with open access at Springerlink.com

\begin{abstract}
The effect of anisotropy on AVO synthetic modelling in Niger delta Derby field has been attempted. The objective of the study is to determine if anisotropic synthetic model can improve amplitude versus offset (AVO) analysis of CDP gathers by comparing them with isotropic synthetic model over shale-gas sand boundaries. Well logs and common depth point (CDP) processed gathers were used for the analysis. The result of the present study revealed that reservoirs in Derby field are overlain by intrinsically anisotropic shale and as such, anisotropic synthetic modelling yields the best fit to CDP gathers than the isotropic synthetic model. However, in conventional processing for AVO analysis, isotropic rather than anisotropic earth models are usually assumed, which could possibly affect the outcome of an AVO-based analysis at large offsets. Therefore, the effect of anisotropy should be incorporated and properly accounted for using the anisotropic synthetic modelling in the processing and interpretation workflows for quantitative AVO analysis in Niger delta to optimise hydrocarbon recovery.
\end{abstract}

Keywords AVO · CDP super gather · Isotropic synthetic · Anisotropic synthetic

C. N. Ehirim

ehirimen@yahoo.com

1 Geophysics Research Group, Department of Physics, University of Port Harcourt, P.O. Box 122, Choba, Port Harcourt, Nigeria

\section{Introduction}

In most processing and interpretation of seismic reflection data, simple isotropic earth models have been assumed. This is largely due to the multiparameter nature of anisotropic earth models arising from geologic complexity of the earth itself, limitations that have affected amplitude versus offset (AVO) analysis for hydrocarbon reservoir characterisation and monitoring (Hilde 2012). However, with the simplification of the anisotropic earth model and the transition from poststack to prestack migration and wider offset and azimuthal coverage of 3D surveys, this isotropic earth assumption has become ineffective and grossly inadequate in anisotropic-based AVO analysis.

Consequently, vertically transverse isotropy (VTI), which is the simplest and most practical anisotropic model typically used to describe sand/shale sequences, has become standard model in the anisotropic analysis of seismic data especially, in AVO analysis (Backus 1962; Li and Pickford 2002). In this type of medium, waves generally travel faster in the horizontal direction, than in the vertical direction. Anisotropy increases with offset (incident angle) and has considerable effects on the amplitude of reflections. The magnitude of anisotropy is dependent on Thomsen (1986) dimensionless anisotropy parameters epsilon $(\varepsilon)$ and delta $(\sigma)$ of the overburden for a compressional wave incident on transversely isotropic media, which determines the strength of the AVO response.

Ignoring the effect of anisotropy in AVO studies has caused the AVO analysis to suffer from ambiguities particularly, when the overburden is anisotropic (Castagna 2000). Therefore, accounting for anisotropy in AVO synthetic modelling will not only lead to a more correct model of the earth but also provide a greater fit to the seismic data contrary to the isotropic earth assumption. Recently, 
seismic anisotropy has become a key part of the processors workflow in creating synthetic earth models that correctly interprets prestack seismic data for AVO reservoir characterisation and monitoring. Computation of compressional wave synthetic in VTI media is based on the 1D assumption that elastic properties vary only with depth (Mallick and Frazer 1991).

Studies on isotropic and anisotropic (VTI) media have been carried out by several authors (Thomsen 1986; Mallick and Frazer 1991; Helbig 1994; Tsvankin 1995a, b; Carcione et al. 1988; Williams and Jenner 2002). The authors reported that the isotropic earth assumption is valid only for a weakly anisotropic or truly isotropic earth media. However, for cases where the overburden is strongly anisotropic as encountered above target horizons, the behaviour of compressional wave amplitudes becomes very complicated and the isotropic earth assumption becomes ineffective. In such instances, the VTI case gives a more correct model of the earth which fits the real seismic data.

The present study is focused on investigating the effect of anisotropy in AVO analysis in the Niger delta Derby field (Fig. 1). AVO isotropic and anisotropic synthetic seismograms were generated and compared to the real prestack seismic gathers to deduce the robust model for anisotropy AVO-based analysis in Derby field.

\section{Geology of the study area}

The Niger Delta is a sedimentary structure formed as a complex regressive offlap of clastic sediments ranging in thickness from 9000 to $12000 \mathrm{~m}$ (Avbovbo 1978). Starting as separate depocentres, the Niger Delta has coalesced to form a single united system since Miocene. The Niger delta, according to Short and Stauble (1967), is consist of three distinct lithofacies designated from bottom to top as Akata Formation, Agbada Formation, and Benin Formation (Fig. 2).

The Akata Formation is the basal major time-transgressive lithologic unit in the Niger delta complex. It is a marine prodelta megafacies, comprising mainly of shales with occasional turbidite sandstones and siltstones and plant remains at the top. It is under-compacted (overpressured) in much of the delta and is believed to have been deposited in front of advancing delta (Short and Stauble 1967). The mature marine shales of the Akata Formation have been suggested to be the source rock of hydrocarbon in the Niger Delta (Doust and Omatsola 1990).

The Agbada Formation, which overlies the Akata Formation, consists of paralic silicic clastics over 3700 metres thick and divided into an upper unit consisting of sandstone-shale alternations with the former predominating over the latter and a lower unit in which the shales predominates. The sandy part constitutes the main hydrocarbon reservoirs and the shales form seals in the delta oilfields (Ejedawe 1981; Evamy et al. 1978; Doust and Omatsola 1990).

The Benin Formation, on the other hand, has been described as "coastal plain sands". It consists mainly of sands and gravels with thicknesses ranging from 0 to $2100 \mathrm{~m}$ (Avbovbo 1978). The sands and sandstones are coarse to fine, granular in texture and partly unconsolidated. For this reason, the Benin Formation, which is generally water-bearing, is the main source of potable groundwater in the Niger Delta area.

\section{Materials and methods}

The dataset used for this study is a full 3D prestack P-wave seismic data processed into CDP super gathers (Fig. 3) and Derby well 1 in the field. The well log data consisting of
Fig. 1 Location map showing Derby Field in the study area

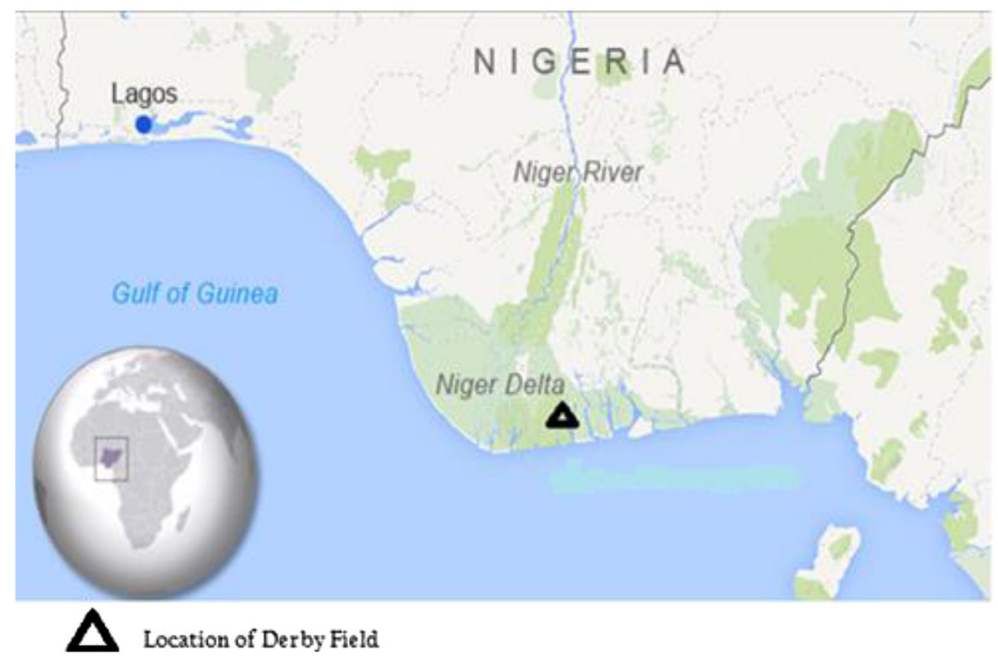


Fig. 2 Geologic and

Stratigraphic succession map of the Niger delta
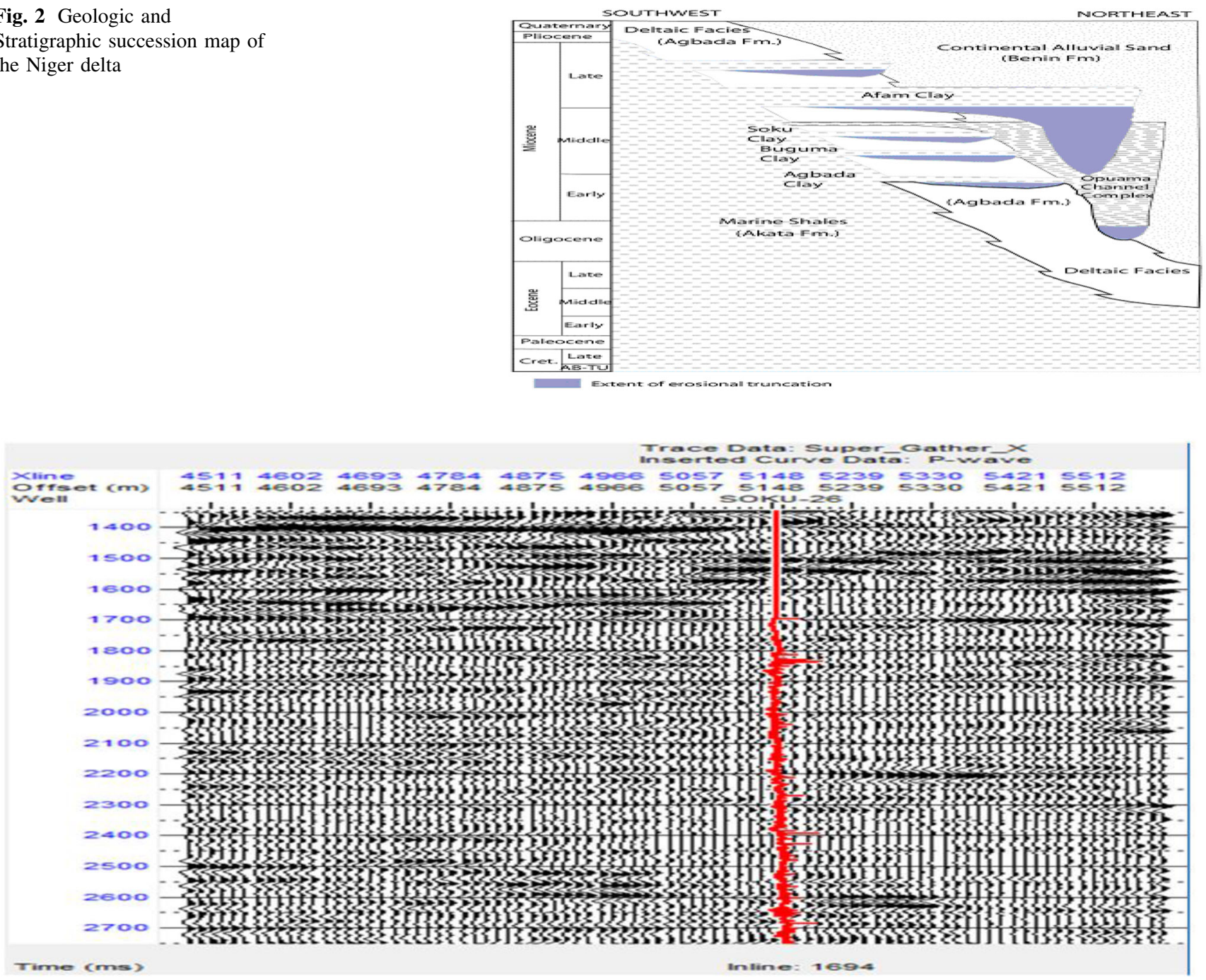

Fig. 3 3D processed CDP super gather with inserted P-wave along inline 1694

compressional or sonic log, gamma ray log, density log, true formation resistivity log, calliper logs, and check shot data were corrected for shale washout effects and de-spiked using median filter to remove high frequency noise and other borehole irregularities.

Well log analysis was performed and three prospective reservoirs zones HDI, HDII, and HDIII were delineated (Fig. 4).

S-wave $\log$ was created using Castagna's mud rock relationship and modelled to the correct S-wave behaviour for gas sand by fluid substitution after rock physics analysis within the reservoir interval. Thomsen's anisotropy well logs (epsilon and delta) were created using the empirical relationship presented by $\mathrm{Li}$ (2002), from gamma ray $\log$ (Fig. 5).

Well log data were check shot corrected and correlated with the prestack data, and a zero phase wavelet was extracted. Subsequently, Shuey's approximate three-term equation to the exact and complex Zoeppritz's equation (Shuey 1985) was used to compute the reflection coefficients versus offset for the isotropic and anisotropic p-wave synthetic gathers for comparison with the real CDP super gather for AVO-based analysis in the field.

To be able to compare the synthetics and real seismic CDP gather more quantitatively, the seismic horizons HDI, HDII, and HDIII corresponding to the prospective gas sand tops were manually picked across each of the isotropic and anisotropic synthetic seismograms and the CDP super gather.

\section{Presentation of results}

The result of the synthetic modelling for anisotropic AVObased analysis in Derby field is shown in Fig. 6, where track 1 is the Vshale, track 2 the resistivity log, tracks 3 and 4 the isotropic and anisotropic synthetic gathers and track 5 


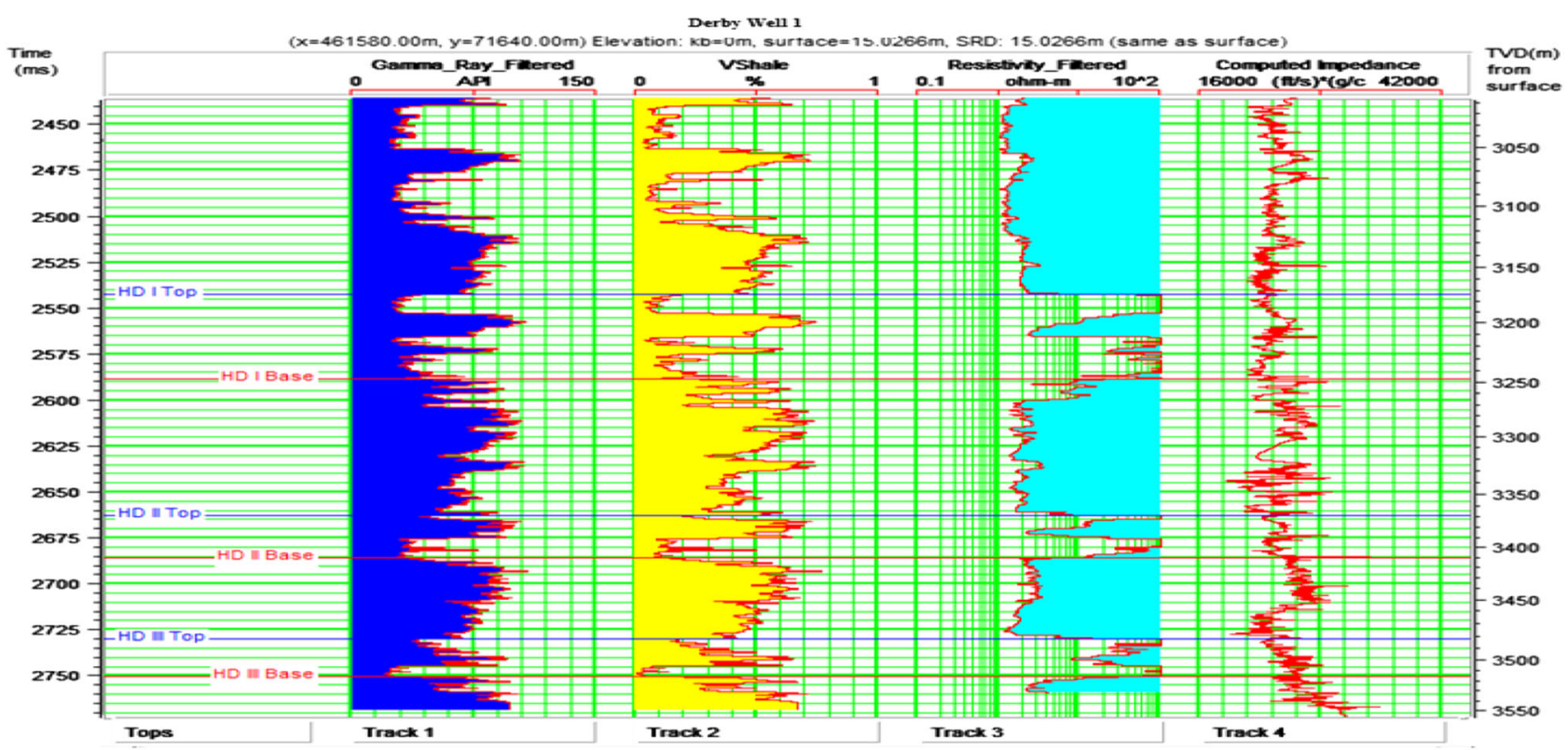

Fig. 4 Derby well 1 showing suite of well logs and mapped reservoir Tops in the study

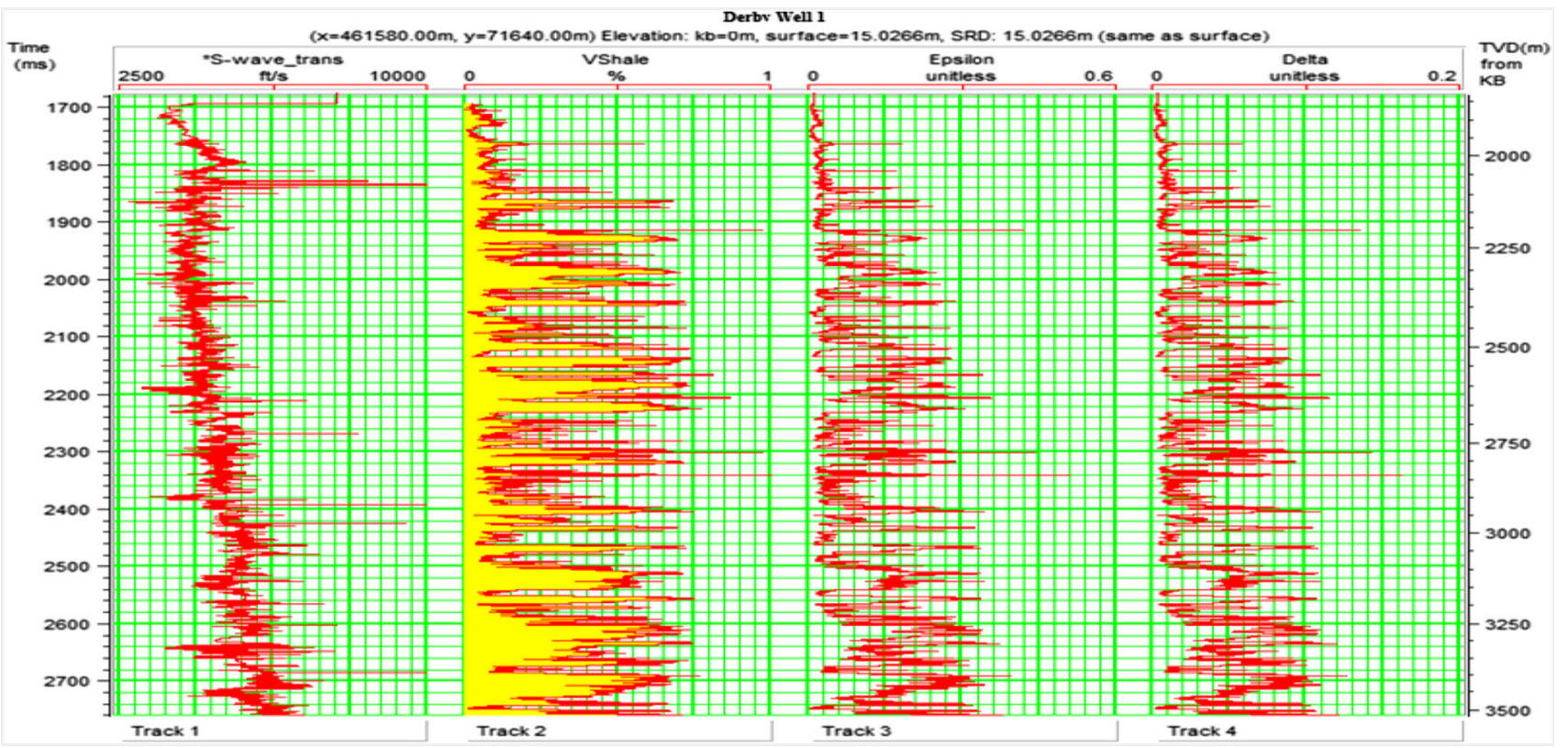

Fig. 5 Computed S-wave log and Thomsen's epsilon and delta anisotropic logs for Derby Well 1 in the study

the real CDP gathers. Results were analysed by comparing the Vshale, resistivity log, isotropic and anisotropic synthetic gathers with the real CDP gather along the seismic horizons.

The result of the synthetic modelling shows that the isotropic and anisotropic synthetic gathers compares favourably well at near offset but at far offset a discrepancy exist. The anisotropic AVO synthetic gather produces sections with better amplitude definitions than the isotropic synthetic gather with increasing offset. The synthetic gathers also show that reflection amplitudes decreases with offset, as for the isotropic and anisotropic synthetics. This observation is an indication that anisotropy increases with offset. However, the increase in amplitude is less for the isotropic than anisotropic synthetic gather.

Analysis of results along the seismic horizons shows that for shallow gas charged reservoir top (HDI), the isotropic and anisotropic synthetic gathers correlate well with the real CDP gather. However, for deeper gas sand charged reservoirs tops HDII and HDIII, overlain by thick 


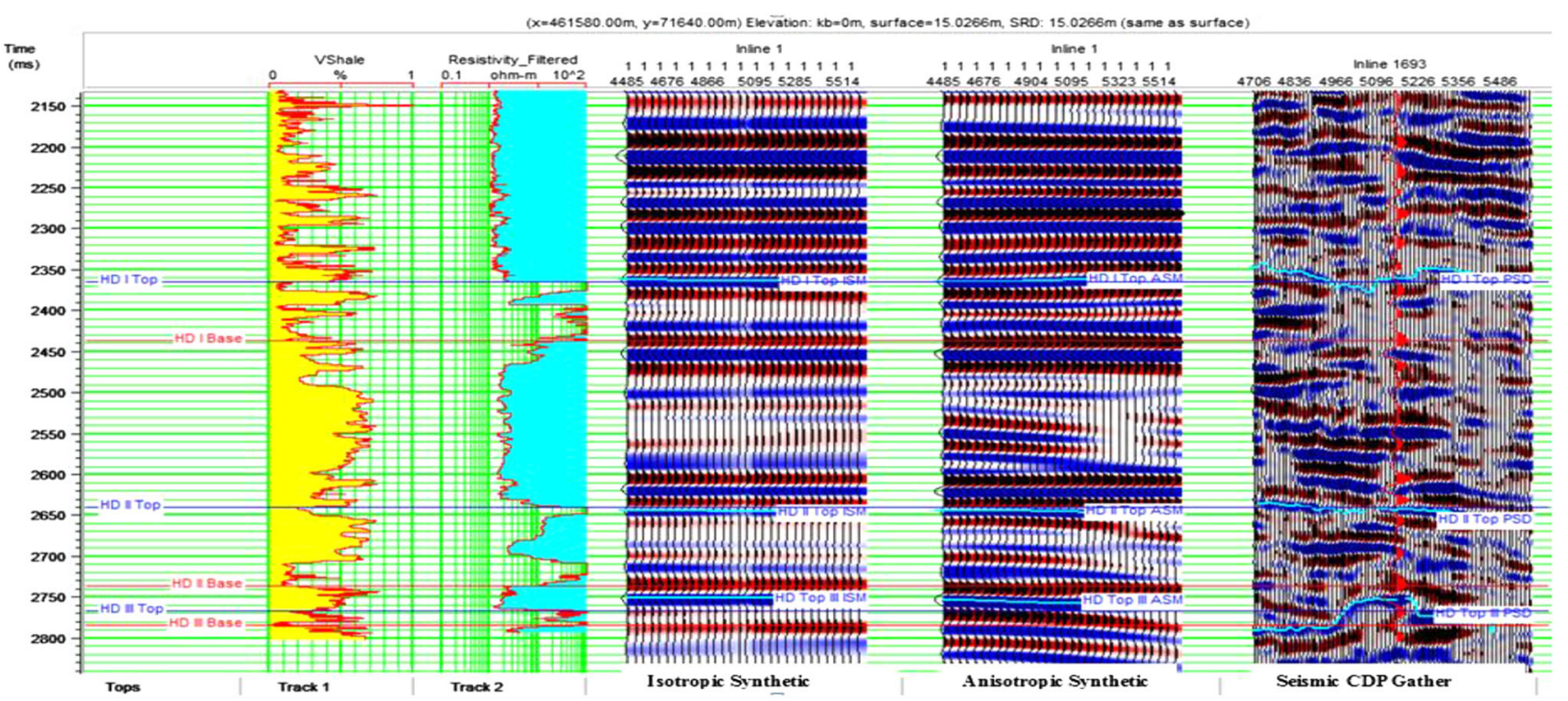

Fig. 6 Comparison of isotropic and anisotropic synthetics with the real CDP super gather in the study

transversely isotropic shale formations, the anisotropic synthetic gather matches the real CDP gather than the isotropic synthetic gather.

Result also shows that shale layers are characterised by decreasing and discontinuous amplitude reflections in the anisotropic synthetic gather, which favourably matches the real data than the discontinuous weak reflections in the isotropic model. This observation suggests that shales are more anisotropic than the sands and better modelled with anisotropic than isotropic earth model.

\section{Discussion of results}

The effect of anisotropy on AVO synthetic modelling was carried out around Derby well 1 location where isotropic and anisotropic synthetic gathers were generated and compared with real CDP gathers along seismic horizons HDI, HDII, and HDIII in Derby field southeastern Niger delta.

The result of study shows that the isotropic and anisotropic synthetic gathers show large amplitude decreases with offset along the HDI, HDII, and HDIII seismic horizons. However, this amplitude decreases with offset is less for the isotropic gather than the anisotropic gather. This discrepancy in AVO response between the isotropic and anisotropic synthetic gathers is largely attributed to the contrast in $\Delta \varepsilon$ and $\Delta \sigma$ of Thomsen (1986) anisotropic parameters on both sides of the interface separating the overlying shale bed and reservoir gas sand for a compressional wave incident on a transversely isotropic media. This contrast in anisotropic parameters across the interface will induce larger amplitude response in the anisotropic than the isotropic gathers comparable to the real CDP gathers with increasing offsets (Tsvankin and Thomsen 1994).

The observed amplitude decrease with offset is characteristics of a class IV AVO anomaly (bright spot) for direct hydrocarbon indications in the field (Castagna and Swan (1997). This is a low impedance boundary with unconsolidated sand comparable to class III, but overlain by consolidated shale (Castagna et al. 1998). The HDI, HDII, and HDIII gas sand reservoir tops have negative reflections (soft kick in blue) which indicates a less consolidated gas sand overlain by consolidated shale typical of the Niger delta petroleum system (Doust and Omatsola 1990). The base of the reservoir sands has positive reflection (hard kick in red) suggesting a less consolidated hydrocarbon sands over consolidated shale bed.

Analysis of results along the seismic horizons shows that for shallow gas charged reservoir top (HDI), the isotropic and anisotropic synthetic gathers correlate well with the real CDP gather. However, for gas sand charged reservoirs tops HDII and HDIII, overlain by thick transversely isotropic shale beds, the anisotropic synthetic gather matches the real CDP gather than the isotropic synthetic gather. This is an indication that with increasing anisotropic overburden (increasing shale content), the anisotropic synthetic gather yields the best fit to the real CDP gather than the isotropic synthetic gather with characteristics non-hyperbolic moveout (Tsvankin and Thomsen 1994).

Generally, the anisotropic synthetic model produces a better stack response which improves event continuity and structural definition than the isotropic model, especially at far offsets. These results are very important because most 
of the exploration and production of hydrocarbons in the Niger delta are now focused at deeper targets where long offset seismic data acquisition is a common practice. Therefore, interpretation of seismic data with anisotropic synthetic AVO model will ensure that the reservoir is better imaged and characterised while the isotropic synthetic AVO model provides possibility for a misinterpretation, which is a disadvantage in hydrocarbon exploitation in the region.

\section{Conclusion}

The result of the present study revealed that reservoirs in Derby field is overlain by intrinsically anisotropic shale and as such, anisotropic synthetic modelling yields the best fit to data than the isotropic synthetic model for AVObased analysis. However, in conventional processing for AVO analysis, isotropic rather than anisotropic earth models is usually assumed which could possibly affect the outcome of an AVO analysis at larger offsets based on the result of this study. Therefore, the effect of anisotropy should be incorporated and properly accounted for in the processing workflows for any quantitative AVO analysis in Niger delta to optimise hydrocarbon recovery.

Open Access This article is distributed under the terms of the Creative Commons Attribution 4.0 International License (http:// creativecommons.org/licenses/by/4.0/), which permits unrestricted use, distribution, and reproduction in any medium, provided you give appropriate credit to the original author(s) and the source, provide a link to the Creative Commons license, and indicate if changes were made.

\section{References}

Avbovbo AA (1978) Tertiary lithostratigraphy of Niger delta. Am Assoc Pet Geol Bull 62:295-300

Backus GE (1962) Long-wave elastic anisotropy produced by horizontal layering. J Geophys Res 67:4427-4440
Carcione J, Kosloff D, Kosloff R (1988) Wave-propagation simulation in anelastic anisotropic (transversely isotropic) solid. J Mech Appl Math 41:319-345

Castagna JP (2000) AVO analysis. CSEG Rec 26(6):47-70

Castagna JP, Swan HW (1997) Principle of AVO cross plotting. ARCO exploration and production technology. University of Oklahoma, Norman

Castagna JP, Swan HW, Foster DJ (1998) Framework for AVO gradient and intercept interpretation. Geophysics 63:948-956

Doust H, Omatsola E (1990) Niger delta. In: Edwards JD, Santogrossi PA (eds) Divergent/passive Margin Basins, AAPG Memoir 48: Tulsa. American Association of Petroleum Geologists, pp 239-248

Ejedawe JE (1981) Patterns of incidence of oil reserves in Niger delta basin. Am Assoc Pet Geol 65:1574-1585

Evamy BD, Herebourne J, Kameling P, Knap WA, Molley FA, Rowlands PH (1978) Hydrocarbon habitat of Tertiary Niger delta. Am Assoc Pet Geol Bull 62:1-39

Helbig K (1994) Foundations of elastic anisotropy for exploration seismics. Pergamon Press, London

Hilde H (2012) Estimation of anisotropy parameters and AVO modeling of the Troll Field, North sea. Master's thesis, Norwegian University of Science and Technology (NTNU), Norway

Li Y (2002) Anisotropic well logs and their applications in seismic analysis. SEG Expanded Abstracts

Li Y, Pickford S (2002) Anisotropic well logs and their applications in seismic analysis. SEG int'l exposition and 72nd annual meeting

Mallick S, Frazer LN (1991) Reflection/transmission coefficients and azimuthal anisotropy in marine seismic studies. Geophys J Int 105:241-252

Short KC, Stauble AJ (1967) Outline of geology of Nigeria. Ibadan University Press, Ibadan, pp 90-97

Shuey RT (1985) A simplification of the Zoeppritz's equations. Geophysics 50:609-614

Thomsen L (1986) Weak elastics anisotropy. Geophysics 51(10):1954-1966

Tsvankin I (1995a) Seismic wave fields in layered isotropic media. Samizdat Press, Colorado School of Mines

Tsvankin I (1995b) Body-wave radiation patterns and AVO in transversely isotropic media. Geophysics 60:1409-1425

Tsvankin I, Thomsen L (1994) Nonhyperbolic reflection moveout in anisotropic media. Geophysics 59:1290-1304

Williams M, Jenner E (2002) Interpreting seismic data in the presence of azimuthal anisotropy; or azimuthal anisotropy in the presence of the seismic interpretation. Lead Edge 21:771-774 